\title{
Gender and ethnic differences in young adolescents' sources of cigarettes
}

\author{
Leslie A Robinson, Robert C Klesges, Susan M Zbikowski
}

\begin{abstract}
Objective-To identify the sources used by young adolescents to obtain cigarettes. Design-In early 1994 a survey assessing usual sources of cigarettes and characteristics of the respondents was administered in homeroom classes.

Setting-A large urban, predominantly African American school system.

Subjects-A population-based sample of 6967 seventh graders averaging 13 years of age.

Main outcome measure-Reports of usual sources of cigarettes.

Results-At this age level, young smokers were more likely to get cigarettes from friends $(31.2 \%)$ than buy them in stores $(14.3 \%)$. However, the odds of purchasing varied for different groups of children. Regular smokers were much more likely $(48.3 \%)$ to have purchased cigarettes than experimental smokers $(9.6 \%), p<0.001$. Girls were less likely to have bought their cigarettes than boys $(p<0.001)$, and black smokers were less likely to have purchased cigarettes than white children $(p<0.001)$. Results suggested that family members who smoke may constitute a more important source of tobacco products than previously recognised, particularly for young girls.

Conclusions-In this middle-school sample, peers provided the major point of cigarette distribution. However, even at this age, direct purchase was not uncommon. Sources of cigarettes varied significantly with gender, ethnicity, and smoking rate.

(Tobacco Control 1998;7:353-359)
\end{abstract}

Keywords: gender, ethnicity, adolescents, cigarette sources

\section{Introduction}

Despite prevention efforts, cigarette smoking among the young continues to be a major public health concern. Although the proportion of children who smoke declined significantly during the 1970s, it stabilised over the next decade $^{1}$ and in recent years has increased markedly. ${ }^{2}$ For example, in $199127.5 \%$ of high school students smoked, but by 1995 that number had risen to $34.8 \% .^{2}$ For these young smokers the consequences of tobacco use are serious, even in adolescence: Children who smoke are more likely to have a variety of health problems, including upper respiratory tract infections, reduced lung growth, and retardation in the level of maximum lung function. ${ }^{1}$ Further, many adolescent smokers will become long-term consumers of tobacco products. In fact, research has suggested that between $33 \%$ and $50 \%$ of those who experiment with cigarettes escalate to regular use. $^{3-5}$ Once tobacco consumption is established, these young smokers will be addicted for an estimated 16 to 20 years. ${ }^{6}$

In an effort to curb smoking among adolescents, all states and the District of Columbia have enacted laws banning the sale of tobacco to minors. However, active enforcement of these tobacco distribution laws has been rare. ${ }^{7}$ Not surprisingly, then, most children have found cigarettes to be readily accessible. For example, in studies of high school students, between $55 \%$ and $82 \%$ of those surveyed thought it would be easy to get cigarettes. ${ }^{8-10}$ Even among students well below the legal age of purchase, access has not been viewed as problematic. For instance, over half of a large sample of seventh graders (aged 13 years) recently reported that it would be easy to get cigarettes. ${ }^{11}$ Further, the perception of cigarettes as accessible was a significant risk factor for actual tobacco use: children who thought cigarettes were easy to get were more than twice as likely to experiment with them as children who viewed cigarettes as less readily available. ${ }^{12}$ Similar results have also been obtained by other researchers examining the relationship between tobacco availability and patterns of use among children. ${ }^{13}$

Concern about the continuing availability of tobacco products and the consequences of their accessibility has sparked renewed interest in tobacco regulation. In response, a pioneering Food and Drug Administration (FDA) rule was enacted in the United States in 1996 with the aim of reducing tobacco consumption in young people by $50 \%$ over seven years. In February 1997, the first of its provisions went into effect, one which mandated age verification for all over-thecounter sales. (The FDA's jurisdiction over tobacco products was called into question by a ruling on 14 August 1998, by the Fourth Circuit Court of Appeals. This decision is currently stayed pending appeal.)

It seems likely that the FDA provision will have its most immediate impact on young smokers who obtain their cigarettes from stores. However, how large a proportion of adolescent smokers actually buy their cigarettes over the counter remains unclear. To date, there have been surprisingly few studies of the sources through which children obtain cigarettes. Further, the studies that have been 
conducted have obtained somewhat inconsistent results. The reasons for these varying results are not entirely clear, but may reflect differences in the ages of the children sampled or in the exact wording of questionnaires on sources. For example, the proportion of young people who directly purchase their cigarettes from any source has been found to vary from $41 \%$ in a study of high-school students ${ }^{2}$ to $71 \%$ in a study of 10-17 year olds. ${ }^{14}$ Further, a recent report ${ }^{2}$ using the 1995 Youth Risk Behavior Survey found that only $2.2 \%$ of a large sample of high-school students acknowledged using vending machines as a usual source of tobacco, whereas two earlier studies using ninth ${ }^{9}$ and tenth grade $^{15}$ samples obtained rates of approximately $25 \%$ to $50 \%$. One limitation of most of these studies is that their samples consisted primarily of older adolescents, so that little information is available regarding the sources through which young teenagers obtain their first cigarettes. Moreover, with a couple of exceptions, ${ }^{1416}$ these studies generally restricted their samples to current smokers, such as those smoking at least weekly. Thus, data are needed on the sources used by children engaged in the earliest phases of irregular experimental smoking. Such data are critical to develop effective methods for halting the progression from casual irregular smoking towards regular tobacco use. Finally, previous researchers have rarely addressed gender and ethnic differences in sources of tobacco. Such differences may be important: the onset of smoking is typically later for girls and young black people, ${ }^{17}$ suggesting that they may be less effective at accessing the usual routes to tobacco products employed by young white males.

The purpose of the current study is to assess the popularity of a variety of sources through which young adolescents obtain cigarettes. To determine whether sources vary with smoking frequency, data are presented separately for experimental smokers and those who consume cigarettes regularly. In addition, we explore gender and ethnic differences in sources of cigarettes. These data are derived from the Memphis Health Project, a six-year prospective study of the causes of adolescent smoking.

\section{Methods}

OVERVIEW

The entire seventh-grade class in a large, midsouth urban school system comprised the target population. Administrative support for the study was excellent, with all 39 eligible schools participating. Data were collected in the spring of 1994 in homeroom classes, with classroom teachers distributing the questionnaires to the students. Before collecting the data, passive parental consent was obtained; that is, parents were notified of the study and instructed to call our offices if they wished to remove their child from the study. In addition, children participating in the research signed a consent form outlining their rights and the purpose and procedures of the study. For example, the students were told that the survey was about smoking and health, and that participation was voluntary. Because the larger study was longitudinal, strict anonymity could not be ensured, as some form of identification was required to link a given student's responses across years. However, a number of procedures were used to reassure students that their responses would be confidential. For instance, students wrote an identification number instead of their names on the surveys. Further, teachers were told not to assist the students once the survey began, and after completing the questionnaire, the children were instructed to seal it in an unmarked envelope. These envelopes were then sealed in a box prominently marked "confidential". Although the possibility cannot be ruled out that smoking was underreported because of student concerns about privacy, it should be noted that the rates of smoking reported by our sample are comparable to those obtained in other large-scale studies. ${ }^{1}$

Under these conditions students were quite cooperative: only $3 \%$ declined to participate in the study. Another $2 \%$ of the children were lost to the study because of parental refusal or our inability to notify the parents of the research. An additional $16 \%$ of the population of 8828 children did not complete the study because of absenteeism or problems with survey administration. Notably, in this school system at least $9 \%$ of the students are absent on any given day (K Pruett, personal communication, 20 October 1995). Altogether, $79 \%$ of the seventh graders completed the survey. The characteristics of our final sample of 6967 respondents closely match those of the target population in this school system. The participants averaged 13 years of age, with $80.8 \%$ black, $16.5 \%$ white, and $2.7 \%$ listing other ethnic backgrounds. Males and females were equally represented (49.5\% and $50.5 \%$, respectively).

\section{MEASURES}

For the larger study, a questionnaire was constructed to measure a number of variables thought to be related to smoking onset. Among these variables were two dichotomous items designed to assess the perceived availability of cigarettes. On one, students reported whether or not they believed cigarettes would be easy to obtain. The second item asked children whether or not they thought cigarettes were too expensive.

Students were also asked a dichotomous item inquiring about whether or not most of their family members smoked. To allow for non-nuclear family structures-for example, children who live with grandparents or other extended family members-we intentionally focused on family models in general rather than on parental smoking. Thus, smoking among any family member, including siblings, is reflected in this item.

Because we suspected that some sources of cigarettes might be more popular among more deviant youth, a measure of risk-taking and rebellious behaviour was developed for use in this study. The scale consisted of five four-point items scored from 0 to 3, with higher scores indicating greater rebelliousness 
(Cronbach's $\alpha=0.78)$. For example, students were asked how often they like to take risks, with responses ranging from "very often" to "hardly ever." Using these same response options, another item asked students how frequently it is worth getting into trouble to have fun. Scores on the five items were averaged, and each student's average score was standardised. As expected, analysis revealed that students scoring high on the rebelliousness scale felt less supported and successful $(\mathrm{r}[6352]=-0.29, \mathrm{p}<0.001)$, had more friends who smoked $(\mathrm{r}[6530]=0.33, \mathrm{p}<0.001)$, rated the instrumental value of cigarettes more highly $(\mathrm{r}[6279]=0.41, \mathrm{p}<0.001)$, and were more likely to have smoked. ${ }^{12}$ Thus, the rebelliousness measure showed convergent validity with related constructs.

Students who smoked were also asked to indicate where they usually obtained their cigarettes. The following five response options were provided: (1) "I buy them from a store"; (2) "I buy them from a vending machine"; (3) "My friends give them to me"; (4) "I take cigarettes without any adults knowing"; and (5) "other". Students were encouraged to identify all of the sources that applied.

Finally, students' use of cigarettes was measured by self-report. These data were then used to group students into three categories. "Nonsmokers" included those students who reported never smoking, not even a few puffs. "Experimental smokers" consisted of those who admitted to irregular smoking behaviours ranging from having had a single cigarette "just to try" up to smoking three cigarettes a month. "Regular smokers" were those who reported consuming cigarettes at least weekly.

ANALYSIS

In this set of data, three basic questions were addressed. First, we calculated the proportions of young smokers who used each source, both for smokers who relied on only a single source and for the sample as a whole (allowing for multiple responses). Second, $\chi^{2}$ analyses were conducted to examine the relationship between the use of a given source and level of smoking. For example, the proportion of regular smokers who bought cigarettes in stores was compared with that of experimental smokers. Third, the characteristics of those using different sources were explored. For analyses involving continuous data (for example, our measure of rebelliousness) analysis of variance was conducted to identify group differences. Dichotomous data were analysed using $\chi^{2}$ and logistic regression. (In these analyses, we used students rather than schools as the unit of analysis. Although this practice is common in studies of adolescent smoking, it should be noted that to the extent that outcomes are correlated within schools, variance may be underestimated and tests of significance inflated. However, intraclass correlations for the various sources of tobacco were modest (ranging from 0.003 to 0.027 ), and the group differences reported here were robust. As such, we opted to report results from the simpler student-level analyses.)

\section{Results}

PREVALENCE OF CIGARETTE USE

Results concerning the prevalence of smoking in our sample have been previously reported. ${ }^{11}$ Briefly, we found that tobacco use was quite common, even at this young age. Of those reporting their history of cigarette use ( $n=$ 5852), 29.5\% were already experimenting with cigarettes, and another $4.1 \%$ were regular smokers.

(Of the total sample of 6967 students, $16 \%$ did not report their smoking status. In comparison with those who did complete this item, the non-responders were significantly more rebellious $(F[1,6588]=44.38, \mathrm{p}<0.001)$ and more likely to have close friends who smoked $(F[1,6878]=25.90, \mathrm{p}<0.001)$. In addition, non-responders felt less supported and successful $(F[1,6577]=69.60, \mathrm{p}<0.001)$, and they were more likely to view cigarettes as affordable $(\mathrm{OR}=1.22, \mathrm{p}<0.05)$ and as an effective route to enhancing their social image $(F[1,6542]=9.12, \mathrm{p}<0.01)$. All of these characteristics have been previously associated with a greater likelihood of cigarette smoking. ${ }^{12}$ Thus, it should be noted that the base rate of cigarette smoking may be somewhat underestimated in this sample.)

Further analysis revealed that the probability of experimenting with cigarettes did not vary reliably by ethnicity or gender. However, regular smoking was significantly more prevalent among boys than girls. Whereas $5.8 \%$ of the boys reported smoking at least once a week, only $3 \%$ of the girls admitted using tobacco at this level. The ethnic difference was even more pronounced: $13.1 \%$ of the white children were regular smokers, vs only $2.3 \%$ of the black youngsters.

NUMBER OF SOURCES OF TOBACCO

Of the 1969 children who were experimenting with cigarettes or smoked regularly, $65.9 \%$ acknowledged at least one source of cigarettes. (The $34.1 \%$ of the children who reported having smoked without identifying a source were much more likely to be irregular smokers than were children who did list at least one source $(\mathrm{OR}=29.7, \mathrm{p}<0.001)$. These infrequent smokers may not have responded to the sources item because they did not view it as relevant to themselves. As a result, the sources used by infrequent smokers are underrepresented in our data on the total sample; however, we should note that, nonetheless, the sample of experimental smokers who did respond to the item is quite large $(n=1726)$.) The number of sources used by a single adolescent ranged from 1 to 5, with most young smokers $(52.6 \%)$ indicating that they had only one usual source of tobacco. Experimental smokers were significantly less likely to report using multiple sources of cigarettes than regular smokers $(t[253.80]=$ $9.01, \mathrm{p}<0.001$ ). Black children (who were less likely to be regular smokers) reported using fewer sources than white youngsters $(t[330.99]=8.05, \mathrm{p}<0.001)$. There was no significant difference in the number of sources used by boys $v s$ girls. 
Table 1 Usual sources of cigarettes for seventh graders (13 year olds)

\begin{tabular}{|c|c|c|c|}
\hline \multirow[b]{2}{*}{ Source of cigarettes } & \multirow[b]{2}{*}{$\begin{array}{l}\text { All smokers } \\
n=1969 \\
\%(S E)\end{array}$} & \multicolumn{2}{|l|}{ Prevalence of smoking } \\
\hline & & $\begin{array}{l}\text { Experimental smokers } \\
n=1726 \\
\%(S E)\end{array}$ & $\begin{array}{l}\text { Regular smokers } \\
n=242 \\
\%(S E)\end{array}$ \\
\hline "My friends give them to me." & $31.9(0.01)$ & $28.4(0.01)$ & $57.0(0.03)$ \\
\hline "I buy them from a store." & $14.3(0.01)$ & $9.6(0.01)$ & $48.3(0.03)$ \\
\hline "I buy them from a vending machine." & $7.0(0.01)$ & $4.2(0.01)$ & $26.9(0.03)$ \\
\hline \multicolumn{4}{|l|}{ "I take cigarettes without any adults } \\
\hline knowing." & $16.6(0.01)$ & $14.8(0.01)$ & $29.3(0.03)$ \\
\hline Other source & $17.7(0.01)$ & $16.3(0.01)$ & $27.7(0.03)$ \\
\hline
\end{tabular}

Subjects were allowed to report multiple sources for getting cigarettes, and some smokers did not report their sources.

$\mathrm{SE}=$ standard error for proportion.

Table 2 Logistic regression models comparing students that use a given source with those that do not

\begin{tabular}{llll}
\hline Source of cigarettes & Predictor & Odds ratio & 95\% CI \\
\hline "My friends give them to me.” & Ethnicity & 1.72 & $1.78-3.43$ \\
& Gender & 1.54 & $1.19-1.87$ \\
"I buy them from a store" $\dagger$ & Ethnicity $\times$ gender & 0.61 & $0.39-0.96$ \\
& Ethnicity & 1.72 & $1.30-2.28$ \\
"I buy them from a vending machine." $¥$ & Gender & 1.54 & $1.19-2.00$ \\
"I take cigarettes without any adults & Ethnicity & 4.31 & $2.99-6.20$ \\
knowing." $\$ & Gender & 2.42 & $1.63-3.58$ \\
& Ethnicity & 1.04 & $0.78-1.40$ \\
\hline
\end{tabular}

$\mathrm{n}=1916$. The dependent variables are coded so that use of a source $=1$ and its non-use $=0$.

Ethnicity is coded with white students $=1$ and black students $=0$. Gender is coded with males

$=1$ and females $=0$.

${ }^{\star}$ Model $\chi^{2}[3]=44.82, \mathrm{p}<0.001$

†Model $\chi^{2}[2]=25.80, \mathrm{p}<0.001$

$\ddagger$ Model $\chi^{2}[2]=84.04, \mathrm{p}<0.001$

$§$ Model $\chi^{2}[2]=15.00, \mathrm{p}<0.001$

$\mathrm{CI}=$ confidence intervals.

USE OF SINGLE SOURCES

When children get cigarettes from a single source, which one are they most likely to use? To address this issue we examined data for the 1035 young smokers who reported that they used only one source for cigarettes (students endorsing multiple sources were excluded from this analysis). The results indicated that peers were the most popular source, with $38.4 \%$ of the students reporting that they got their cigarettes only from friends. Another $16.3 \%$ of the children who endorsed only a single source reported that they took them without an adult's knowledge. Surprisingly, a sizeable number of these children reported buying their cigarettes exclusively, either in a store $(15.0 \%)$ or vending machines $(4.3 \%)$. An additional $26 \%$ of the youngsters reported using some other single source.

Some might wonder whether particular sources were accessed by different types of children. To explore this possibility, we compared the characteristics of students who used different routes to tobacco products. The results indicated that youngsters who bought their cigarettes (either in stores or vending machines) were more likely to be regular smokers than those who used other sources $\left(\chi^{2}[1]=72.64, \mathrm{p}<0.001\right)$. In addition, young purchasers were more rebellious than those who got cigarettes through other means $(F[1,1123]=29.59, \mathrm{p}<0.001)$, and they felt less supported and successful $(F[1,1115]=$ 18.28, p<0.001). Further, students who bought cigarettes were more likely to view them as affordable $\left(\chi^{2}[1]=12.64, \mathrm{p}<0.001\right)$ and easily accessible $\left(\chi^{2}[1]=9.75, \mathrm{p}<0.01\right)$.
Thus, students who used direct purchase as their sole route to cigarettes at this early age showed a number of characteristics that have been associated with significant and persistent tobacco use.

USE OF ALL SOURCES

Although most students reported using only one source, many youngsters did endorse multiple methods for obtaining tobacco. To allow for those who did use more than one source, we recalculated the rates of use for each source, this time including all of those endorsed by the students. Table 1 presents these data for the entire smoking sample, as well as for experimental and regular smokers separately. As might be expected, all sources of tobacco are more frequently used by regular smokers than experimental smokers. For both groups, friends again constituted the most common source of tobacco: almost a third of the children reported getting at least some of their cigarettes from peers. In addition, a substantial $16.6 \%$ of the sample admitted to taking cigarettes without an adult's knowledge. Results further indicated that rates of direct purchase varied considerably, depending on how regularly a child smoked. For example, among the experimental smokers only $9.6 \%$ reported that they usually bought their cigarettes in stores, and vending machine usage was even less common (4.2\%). In contrast, almost half of the regular smokers bought their cigarettes in stores, and over $25 \%$ of them reported using vending machines regularly. Thus, the regular smokers were significantly more likely to purchase cigarettes directly from a store $\left(\chi^{2}[1]=260.31, p<0.001\right)$ or a vending machine $\left(\chi^{2}[1]=166.82, \mathrm{p}<0.001\right)$ than were less frequent smokers.

GENDER AND ETHNIC DIFFERENCES IN SOURCES OF CIGARETTES

To assess gender and ethnic differences in sources of cigarettes, a series of logistic regressions were conducted, using ethnicity, gender, and their interaction to predict use of each source. The results of these analyses for each source of cigarettes are presented in table 2 . Turning first to the model predicting students who used friends as a source, one can see that the main effects for ethnic group and gender were both significant, along with their interaction. Follow up of the interaction revealed that black boys were $49 \%$ more likely to get cigarettes from their friends than were black girls $(\mathrm{OR}=1.49, \mathrm{p}<0.001)$. In contrast, there was no gender difference among white students (OR $=0.91, \mathrm{p}>0.05)$.

For the other sources reported in table 2, the interaction of ethnicity and gender was not significant; thus, in each equation the interaction term was dropped in favour of the more parsimonious main effects model. As can be seen, both stores and vending machines were much more likely to be used by white children than by young black smokers. Similarly, boys were significantly more likely than girls to buy cigarettes at both of these outlets. The odds of stealing cigarettes, on the other hand, did not 
vary by ethnicity. However, there was a main effect of gender, such that girls were significantly more likely to report that they have taken cigarettes without an adult's knowledge. This last result held true even when gender differences in smoking rates were taken into account. For example, among experimental smokers, $18.1 \%$ of the girls reported stealing cigarettes compared with only $11.3 \%$ of the boys $\left(\chi^{2}[1]=15.85, p<0.001\right)$. Similarly, among regular smokers more girls $(37 \%)$ than boys $(25 \%)$ reported taking cigarettes without permission $\left(\chi^{2}[1]=3.89, \mathrm{p}<0.05\right)$.

\section{UNDERSTANDING THE GENDER DIFFERENCE IN} STEALING

Why might girls be more likely to steal cigarettes? One possibility involves gender differences in the personality characteristics of young smokers. For example, the girls that do smoke at this young age might be more rebellious than the boy smokers, for whom the behaviour is more normative in early adolescence. However, analysis revealed that girl smokers were generally less rebellious $($ mean $=0.35)$ than boy smokers (mean $=$ $0.71 ; F[(1,1895]=34.63, \mathrm{p}<0.001)$. Further, there was no significant interaction of gender and the tendency to take cigarettes.

Another reason for girls' greater propensity for taking cigarettes might involve their inability to afford them. If so, then perceptions of cost should be related to the probability of stealing. However, analysis revealed that perception of cigarettes as too expensive was unrelated to the probability of stealing both in the sample as a whole $\left(\chi^{2}[1]=0.10, \mathrm{p}>0.05\right)$ and for boys and girls separately $\left(\chi^{2}[1]=0.43\right.$, $\mathrm{p}>0.05$ and $\chi^{2}[1]=0.03, \mathrm{p}>0.05$, respectively).

We then considered whether family smoking might provide the key to understanding girls' propensity for taking cigarettes. Rather than stealing them from stores, these children might be taking cigarettes from family members without permission. If so, then children whose family members smoked would probably be more likely to view cigarettes as easy to get than those with non-smoking families. Indeed, analysis of our sample supported just such a relationship: whereas $54.7 \%$ of the children whose family members smoked believed it would be easy to get cigarettes, only $45.5 \%$ of those with non-smoking families thought access would not be problematic $\left(\chi^{2}[1]=\right.$ $50.72, \mathrm{p}<0.001)$. Furthermore, the relationship between family smoking and perceived ease of access appeared to be much stronger for girls than boys. For example, only $41.9 \%$ of girls with non-smoking families thought cigarettes would be easy to get, compared with $55.3 \%$ of girls with smoking families $\left(\chi^{2}[1]=\right.$ $55.34, \mathrm{p}<0.001)$. In contrast, $49.1 \%$ of boys with non-smoking families vs $54.1 \%$ of those with smoking families thought that access would be easy $\left(\chi^{2}[1]=7.18, p<0.01\right)$.

Are children whose families smoke more likely, then, to report taking cigarettes? Our results confirm that youngsters with smoking families were indeed more likely to report stealing cigarettes $(19.6 \%)$ than those with non-smoking families $(14.6 \%)\left(\chi^{2}[1]=8.54\right.$, $\mathrm{p}<0.01)$. However, this effect was limited to girls: adolescent girls whose families smoked were significantly more likely to have taken cigarettes $(23.5 \%)$ than those with nonsmoking families $(17.1 \%) \quad\left(\chi^{2}[1]=6.31\right.$, $\mathrm{p}<0.05)$. In contrast, the effect of family smoking on stealing was not significant for boys $\left(\chi^{2}[1]=1.22, \mathrm{p}>0.05\right)$.

\section{Discussion}

To date few studies have provided data on the sources through which young adolescents obtain tobacco products. The present investigation was designed to address this issue. Results indicated when all sources were considered, a substantial $14 \%$ of our sample of seventh graders routinely purchased cigarettes in stores, and $7 \%$ used vending machines regularly. These findings are consistent with the large body of research indicating that even very young children have little difficulty buying cigarettes. ${ }^{10}{ }^{16}{ }^{18-22}$ Notably, these data were collected before the FDA regulation requiring identification during purchase went into effect. As we track these children over the next few years, we hope to see these numbers decline in response to tighter tobacco control regulations.

Our results further indicated that, at this age level, by far the majority of young smokers do not obtain cigarettes directly from stores. Instead, peers provide the major point of distribution at this age, with almost one in three young smokers reporting their friends as a usual source. Furthermore, we found the prevalence of direct purchase was tied to smoking frequency; specifically, regular smokers were much more likely to buy their cigarettes than experimental smokers. Similar findings have been obtained by other researchers using older samples. ${ }^{289}{ }^{16}$ For example in a study of high-school students, $35.2 \%$ of the regular smokers used stores, compared with only $15.9 \%$ of the lighter smokers. ${ }^{2}$ Taken together, these findings suggest that as children progress toward heavier addiction they are more likely to resort to buying cigarettes. Thus, the most immediate (but not the only) effect of age verification enforcement might be in preventing the escalation of casual experimentation to regular smoking. However, as of yet few studies have examined the actual effect of tobacco regulation on adolescent smoking habits, and the limited findings to date have proven contradictory. For example, one study found that legislation restricting cigarette sales did significantly decrease adolescent tobacco use and that, as might be expected, the decrease was greater for regular smoking than experimental use. ${ }^{23}$ However, another recent investigation found that well-enforced tobacco sales laws did not alter adolescents' perceived access to tobacco or their smoking habits. ${ }^{24}$ Thus, further evaluation research on the empirical effects of such legislation is clearly needed.

In addition to getting cigarettes from friends and merchants, a surprisingly large proportion of our sample (almost 17\%) reported that they 
had taken cigarettes without an adult's knowledge. In contrast, only $4.2 \%$ of students responding to the recent Youth Risk Behavior Survey (CDC) admitted stealing tobacco products, ${ }^{2}$ and in another investigation, only $9.3 \%$ reported shoplifting cigarettes. ${ }^{25} \mathrm{Al}-$ though the reasons for our differing results are not clear, it should be noted that these studies differed from ours in three important respects. First, in both of the previous studies, youths were allowed to report only one source for cigarettes. It seems reasonable to expect that relatively fewer adolescents would use theft as their primary means of access than as an ancillary method. Second, the adolescents surveyed in the previous studies were in high school rather than middle school, and older children may be less likely to steal cigarettes because direct purchase is easier for them. Third, the previous studies ${ }^{25}$ inquired about stealing per $s e$, whereas our own question was much less direct (we asked students whether they had "taken" cigarettes without adults' knowledge). This difference in wording may be important to students, in that they may be less likely to acknowledge directly an illegal act.

Our analyses also revealed clear ethnic and gender differences in sources of tobacco that paralleled smoking rates. For example, white youngsters and boys (groups more likely to smoke regularly) were more likely to get cigarettes from friends and to buy their cigarettes directly than were black youngsters and girls. The gender difference in buying rate was somewhat surprising, in that a number of studies have demonstrated that underage girls are actually more successful at buying tobacco than boys. ${ }^{10} 18{ }^{11}$ However, just because girls can buy cigarettes does not mean that they do. Although the success rate per attempt may be lower for boys, through sheer persistence they may actually complete more purchases than do girls.

Whereas girls were less likely to buy cigarettes or to get them from friends, our data indicated that they were more likely than boys to take cigarettes without an adult's knowledge. This proclivity toward stealing was not tied to greater rebelliousness among girls nor to concerns about the costs of cigarettes. However, family smoking did appear to play an important role. Specifically, we found that young girls whose family members smoked were more likely to have stolen cigarettes than those with non-smoking families. Among boys, however, family smoking was unrelated to reports of taking cigarettes. This pattern of findings is similar to that obtained in a recent survey of 230 tenth graders. ${ }^{10}$ In that investigation, $41 \%$ of girls $v s$ only $18 \%$ of boys whose parents smoked got their cigarettes from home. Viewed together, these results suggest that family members who smoke provide an important source of tobacco for young girls.

The significance of these findings becomes clearer when viewed against the backdrop of previous research. Studies have repeatedly shown that family smoking is more likely to prompt tobacco use in girls than boys. ${ }^{12}{ }^{26-30}$ For example, in other analyses using this sam- ple we found that white girls whose families smoked were over three times more likely to try cigarettes than girls with non-smoking families. In contrast, family smoking was unrelated to experimental tobacco use for white boys. Further, for both genders, family smoking had little impact on the progression to regular smoking. Thus, the primary impact of family smoking on girls appeared to lie in prompting their initial experimentation with cigarettes. ${ }^{12}$

Obviously, both boys and girls have opportunities to take cigarettes from parents and siblings who smoke. Why, then, might girls be particularly responsive to these opportunities? Part of the answer may lie in social attitudes towards tobacco use among girls. Although smoking in women has become increasingly acceptable over the past few decades, there is still evidence that young girls feel more pressure to remain smoke-free than boys. ${ }^{31}$ For example, in this sample of children, girls viewed cigarettes as having less social reinforcement value than did boys, ${ }^{11}$ and other researchers have found that girls are more likely to believe their parents would be upset if they smoked that boys. ${ }^{32-34}$ Not surprisingly, then, girls have been found to be more likely to keep their smoking a secret, ${ }^{35}$ and they generally view cigarettes as being harder to get than do boys. ${ }^{10} 11$ Because they are less comfortable accessing the public sources of tobacco that boys favour, young girls may be particularly responsive to opportunities to secretly "lift" cigarettes from family members. Conversely, boys may be less likely to engage in this behaviour because they are more comfortable with public purchasing.

Overall, our findings have important implications for tobacco control. For example, given that regular smokers are more likely to be purchasers, they appear to be the group most likely to be immediately affected by the FDA age verification procedures. Experimental cigarette use may also be influenced, but additional steps may be required to significantly reduce lower-level tobacco consumption. For example, public health efforts to discourage cigarette access through the family may constitute a powerful supplement to legislative control, especially in light of other research suggesting that tobacco acquisition through family members is common. ${ }^{14}{ }^{25}$ Toward this end, further research is needed to verify more specifically the typical sources of tobacco within the family. For example, do young girls primarily take cigarettes from parents who smoke, or are older siblings the main source? By clarifying this issue, educational efforts to stop access to tobacco through the family can be targeted more precisely.

Several limitations of the present study should be acknowledged. In this investigation only a few sources for cigarettes were examined, and our data suggested that additional routes to tobacco products are important to consider. For example, almost $18 \%$ of our sample indicated that they had obtained cigarettes through a method other than peers, stores, vending machines, and theft. It may be, for example, that a substantial 
number of children receive cigarettes as gifts from adults. Thus, future investigations should explore other possible sources of tobacco products. Second, sources should be specified more precisely. Although our findings regarding the relationship between parental smoking and students' reports of "taking" cigarettes are interesting, further research directly inquiring about theft from parents vs stores is needed. Third, defining frequency of use more clearly would be helpful. In this study, we asked students to endorse all sources that they usually used; however, students may vary in what they consider to be a "usual" source. A more precise method would be to inquire separately about all sources that have ever been used and then about the single most frequently used source. Finally, data are needed to determine how children's sources of tobacco products change as they age. By understanding the access routes at each age level, more effective legislative and educational programmes can be designed to prevent the onset of cigarette smoking throughout adolescence.

This study was supported by a grant (HL50723) form the National Heart, Lung, and Blood Institute (NHLBI). Support was also received from the Centers of Excellence awarded by the State of Tennessee to the Department of Psychology at the University of Memphis.

1 US Department of Health and Human Services. Preventing tobacco use among young people. A report of the Surgeon Gentobacco use among young people. A report of the Surgeon Geners for Disease Control and Prevention, Office on Smoking ers for Disease Control and Prevention, Office on Smoking and Health, 1994. (US Government

2 US Centers for Disease Control and Prevention. Tobacco use and usual source of cigarettes among high school students-United States, 1995. MMWR 1996;45:413-8.

3 Hirschman RS, Leventhal H, Glynn K. The development of smoking behavior: conceptualization and supportive cross-

sectional survey data. 7 Appl Soc Psychol 1984;14:184-206.
McNeill AD. The development of dependence on smoking in children. Br f Addict 1991;86:589-92

5 Henningfield JE, Cohen C, Slade JD. Is nicotine more addictive than cocaine? $B r \mathcal{F}$ Addict 1991;86:565-9.

6 Pierce, JP, Gilpin, E. How long will today's new adolescent smoker be addicted to cigarettes? Am 7 Public Health 1996;86:253-6.

7 US Department of Health and Human Services, Office of Inspector General. Youth access to tobacco. Bethesda, Mary-
land: Department of Health and Human Services, Public land: Department of Health and Human Services, Public Health Service, National Institutes of
Publication No. OEI-02-91-00880.)

8 US Centers for Disease Control. Accessibility of cigarettes to youths aged 12-17 years-United States, 1989 MMWR 1992;41:485-8.

9 Cummings KM, Sciandra E, Pechacek TF, et al. Where teenagers get their cigarettes: a survey of the purchasing habits of 13-16 year olds in 12 US communities. Tobacco Control 1992;1:264-7.

10 Forster JL, Hourigan M, McGovern P. Availability of cigarettes to underage youth in three communities. Prev Med 1992;21:320-8
11 Robinson LA, Klesges RC. Ethnic and gender differences in risk factors for smoking onset. Health Psychol 1997; risk factors

12 Robinson LA, Klesges RC, Zbikowski SM, et al. Predictors of risk for different stages of adolescent smoking in a biracial sample. F Consult Clin Psychol 1997;65:653-62.

13 Bauman KE, Fisher LA, Bryan ES, et al. Antecedents, subjective expected utility, and behavior: a panel study of adolescent cigarette smoking. Addict Behav 1984;9:121-36.

14 DiFranza JR, Eddy JJ, Brown LF, et al. Tobacco acquisition and cigarette brand selection among youth. Tobacco Control 1994;3:334-8.

15 Forster JL, Klepp K.-I, Jeffery RW. Sources of cigarettes for tenth graders in two Minnesota cities. Health Educ Res Theory Pract 1989;4:45-50.

16 Forster JL, Wolfson M, Murray DM, et al. Perceived and measured availability of tobacco to youths in 14 Minnesota communities: the TPOP Study. Am F Prev Med 1997; 13:167-74.

17 Klesges RC, Robinson LA. Predictors of smoking onset in adolescent African American boys and girls. F Health Educ 1995;26:1-7.

18 US Centers for Disease Control. Minors' access to tobacco-Missouri and Texas. MMWR 1993;42:125-8.

19 US Centers for Disease Control. Minors' access to cigarette vending machines-Texas. $M M W R$ 1994;43:625-7.

20 DiFranza JR, Norwood BD, Garner DW, et al. Legislative efforts to prote

21 Erickson 1 , Woodruff SI, Wildey MB, et al. Baseline assessment of cigarette sales to minors in San Diego, California. F Commun Health 1993;18:213-24.

22 Wildey MB, Woodruff SI, Agro A, et al. Sustained effects of educating retailers to reduce cigarette sales to minors. Public Health Rep 1995;110:625-9.

23 Jason LA, Ji PY, Anes MD, et al. Active enforcement of cigarette control laws in the prevention of cigarette sales to minors. FAMA 1991;266:3159-61.

24 Rigotti NA, DiFranza JR, Chang Y, et al. The effect of enforcing tobacco-sales laws on adolescents' access to tobacco and smoking behavior. $N$ Engl f Med 1997; 337:1044-51.

25 Wildey MB, Woodruff SI, Pampalone SZ, et al. Self-service sale of tobacco: how it contributes to youth access. Tobacco Control 1995; 4:355-61.

26 Chassin L, Presson CC, Sherman SJ, et al. Changes in peer and parent influence during adolescence: longitudinal versus cross-sectional perspectives on smoking initiation. Dev Psychol 1986;22:327-34.

27 Malkin SA, Allen DL. Differential characteristics of adolescent smokers and non-smokers. F Fam Pract 1980;10:437-

28 Stanton WR, Silva PA. Children's exposure to smoking. Int f Epidemiol 1991;20:933-7.

29 Swan AV, Creeser R, Murray M. When and why children first start to smoke. Int F Epidemiol 1990;19:323-30.

30 Williams AF. Personality and other characteristics associated with cigarette smoking among young teenagers. $\mathcal{F}$ Health Soc Behav 1973;14:374-80.

31 Murray M, Cracknell A. Adolescents' views on smoking. $\mathcal{f}$ Psychosom Res 1980;24:243-51.

32 Kelson SR, Pullella JL, Otterland A. The growing epidemic: a survey of smoking habits and attitudes toward smoking among students in grades 7 through 12 in Toledo and Lucas County (Ohio) public schools. Am f Public Health 1975;65:923-38.

33 Palmer AB. Some variables contributing to the onset of cigarette smoking among junior high school students. Soc Sci Med 1970;4:359-66.

34 Urberg K, Robbins RL. Adolescents' perceptions of the costs and benefits associated with cigarette smoking: sex differences and peer influence. 7 Youth Adolesc 1981; 10:353-61

35 Goddard E. Why children start smoking: an enquiry carried out
by Social Service Division of OPCS on behalf of the Department of Health. London: HMSO, 1990. 